УДК 621.891

DOI: $10.18372 / 0370-2197.3(88) .14883$

В. А. ВОЙТОВ, А. Г. КРАВЦОВ

Харьковский национальный технический университет сельского хозяйства им. Петра Василенко, Украина

\title{
ТЕОРЕТИЧЕСКИЕ ИССЛЕДОВАНИЯ ПРОЦЕССА ФОРМИРОВАНИЯ МАСЛЯНОЙ ПЛЕНКИ НА ПОВЕРХНОСТИ ТРЕНИЯ ПРИ НАЛИЧИИ ФУЛЛЕРЕНОВ В СМАЗОЧНОМ МАТЕРИАЛЕ
}

\begin{abstract}
В работе представлены результаты теоретических исследований по формированию масляной пленки на поверхности трения при наличии фуллеренов в смазочном материале. Увеличение количества агрегатов (кластеров и мицелл) в объеме смазочного материала увеличивает суммарную напряженность электростатического поля смазочной пленки, которое формируется под действием электростатического поля поверхности трения. При этом, применяя «растворитель» для фуллеренов в виде высокомолекулярных кислот, количество агрегатов увеличивается на порядок. Показано, что для увеличения числа агрегатов, которые будут образовываться в базовом масле, необходимо понижать критическую концентрацию кластеро - и мицеллообразования. Одним из путей снижения критических концентраций является применение «сильных растворителей», например, растительных масел, которые содержат 72 $82 \%$ масс. олеиновой кислоты и неограниченно растворяются в базовых технических маслах.
\end{abstract}

Ключевые слова: смазочный материал; фуллерены; растительные масла; технические масла; электростатическое поле поверхности трения; электростатическое полесмазочного материала; кластеры; мицелль; критическая концентрация агрегатов

Введение. На сегодняшний день большой интерес вызывает применение наноуглеродных присадок и добавок (фуллеренов С60). В ряде работ представлены результаты исследований влияния фуллереновых добавок к смазочным материалам на процессы трения и изнашивания металлов и сделан вывод о перспективности использования таких добавок.

Сложность экспериментальных исследований влияния фуллереновых добавок состоит в том, что невозможно исследовать механизмы взаимодействия активных элементов в смазочной среде в процессе трения и их взаимодействие с поверхностью трения. При этом, поверхность трения в процессе работы трибосистемы под действием пластической и упругой деформаций шероховатостей и материала поверхностного слоя, выступает в качестве «генератора электростатического силового поля», что оказывает влияние на упорядочение структуры тонкой масляной пленки и определяет ее прочность и толщину.

Новые возможности в изучении процессов формирования пленок смазочных материалов, содержащих фуллерены, представляет компьютерное молекулярное моделирование, которое позволяет представить процесс взаимодействия молекул кластеров и мицелл, находящихся в смазочном материале, с «энергетически заряженной» поверхностью трения.

Электрически активные дисперсные системы с развитой удельной поверхностью, к которым относятся кластеры и мицеллы содержащих молекулы фуллерена, являются одним из перспективных классов современных материалов. Данные материалы в ближайшее время будут применяться при разработке но- 
вых смазочных композиций. Сложность строения дисперсных систем на основе наноматериалов, а также наличие локальных неоднородностей, определяют отсутствие представления о механизме снижения износа и на трение в трибосистемах, где в смазочных материалах используются фуллерены. При наличии потерь многочисленных границ раздела в этих сложных системах суммарный эффект межфазных взаимодействий становится особенно сильным и является определяющим для процесса генерации собственных электростатических полей. Такое взаимодействие приводит к возникновению электрических сил и к градиенту электростатического поля у поверхности трения.

Анализ последних публикаций по данной проблеме. Анализ работ, посвящённых применению фуллеренов, как добавок к смазочным материалам, позволяет сделать вывод, что фуллерены не диспергируются во всех технических маслах, как минеральных так и синтетических [1-3]. Это один из больших недостатков фуллеренов. Однако, фуллерены хорошо диспергируются по объему в растительных маслах, особенно высокоолеиновых [4]. Следовательно, используя данное явление можно предварительно диспергировать фуллерены в высокоолеиновом растительном, например, рапсовом масле, а затем ввести данную композицию в смазочный материал. Таким образом можно реализовать механизм мицеллообразования вблизи электростатически заряженной поверхности трения, которая выступает как «генератор электростатического силового поля», что позволит создать прочные поверхностные слои.

В работах [5; 6] выполнены теоретические исследования формирования масляной пленки на поверхности трения при введении фуллеренов в растительное масло с последующим введением в смазочный материал. Математическая модель разработана на основе взаимодействия электрически активных гетерогенных мелкодисперсных систем на границе раздела поверхность трения - смазочная среда и описывается дифференциальным уравнением Пуассона. Показана связь электростатического поля поверхности трения и электростатического поля в объёме жидкости, а также роль поверхности трения на процесс образования кластеров и мицелл в плёнке смазочного материала у поверхности трения. Установлено, что под действием напряженно-деформированного состояния поверхностных слоёв поверхность трения оказывает влияние на формирование электростатического поля в объёме масляной плёнки, имеющей мицеллярное строение [7].

Цель исследований. Целью данной работы является выполнить теоретические исследования формирования масляной пленки на поверхности трения при наличии фуллереновых композиций в смазочном материале.

Методический подход к проведению исследований. В процессе работы трибосистемы поверхности трения, вследствие пластической и упругой деформации поверхностных слоев материала, накапливают поверхностную энергию, размерность Дж/м², которую можно представить как поверхностную плотность заряда, размерность Кл/м².

Данные физические величины зависят от следующих параметров: конструкции трибосистемы (площадей трения и объемов под площадями трения подвижных и неподвижных трибоэлементов); структуры материалов трибоэлементов (внутреннее трение структуры материала, модуль упругости, коэффициент Пуассона); трибологических свойств базовой смазочной среды; шероховатости поверхности трения и среднего шага неровностей $(R a, S m)$; нагрузки и скорости скольжения. Перечислен- 
ные параметры позволяют определить плотность заряда, который накапливается на поверхности трения трибосистемы в процессе работы и рассчитать напряженность электростатического поля поверхности трения [5; 6].

В зависимости от конструкции трибосистемы и режимов ее работы напряженность электростатического поля будет изменяться. Следовательно, поверхность трения трибосистемы можно представить в виде «генератора электростатического силового поля», размерность В/м, величина которого будет оказывать силовое воздействие на смазочную среду, находящуюся вблизи поверхности трения и формировать структуру и толщину смазочной пленки.

Наиболее удобным методом для определения напряженности электростатического поля является решение дифференциального уравнения для потенциала, которое представлено в работе [5]:

$$
\frac{\partial^{2} \varphi}{\partial z^{2}}=-\frac{\rho}{\varepsilon \varepsilon_{0}}=-\left(E_{n}+E_{k}+E_{\mu}\right),
$$

где $\varphi$ - электрический потенциал, В; $z$ - координата, перпендикулярная поверхности трения; $\rho$ - объемная плотность заряда; $\varepsilon$ - относительная диэлектрическая проницаемость базовой смазочной среды; $\varepsilon_{0}$ - диэлектрическая постоянная, равна $8,85 \cdot 10^{-12}$, Кл/В·м или $\Phi /$ м; $E_{n}$ - напряженность электростатического поля создаваемого поверхностью трения в процессе работы, В/м: $E_{n}-$ напряженность электростатического поля в объеме смазочной пленки за счет образования кластеров из фуллеренов, В/м: $E_{M}-$ напряженность электростатического поля в объеме смазочной пленки за счет образования мицелл из фуллеренов и олеиновой кислоты растительного масла, В/м.

Первое слагаемое в правой части уравнения (1) определяет напряженность электростатического поля создаваемого поверхностью трения в процессе работы, которое получило название «генератора электростатического силового поля»:

$$
E_{n}=\frac{\sigma}{2 \varepsilon_{0}}, \mathrm{~B} / \mathrm{M}
$$

где $\sigma$ - поверхностная плотность заряда, Кл/м², определяется по формулам, которые приведены в работе [5].

Второе слагаемое правой части уравнения (1) определяет напряженность электростатического поля в объеме смазочной пленки за счет образования кластеров из фуллеренов:

$$
E_{k}=\frac{n_{k} p_{k}}{4 \pi \varepsilon \varepsilon_{0} d_{k}^{3}}, \mathrm{~B} / \mathrm{M}
$$

где $n_{k}$ - количество кластеров на единицу объема базового смазочного материала, шт; $p_{k}-$ дипольный момент кластеров, содержащих фуллерены, размерность Кл`м; $d_{k}-$ среднее расстояние между кластерами и поверхностью трения, равное среднему размеру (диаметру) кластера, размерность м.

При достижении концентрации молекул фуллеренов в объеме смазочного материала, которую называют критической концентрацией кластерообразования $(K K K)$, образуются агрегаты из однотипных молекул-кластеров. 
Количество кластеров $n_{k}$, которые могут образовывать фуллерены в базовой смазочной среде, можно определить по свободной энергии Гиббса или потенциалу Гиббса, величина которого характеризует изменения в ходе химической реакции [8]:

$$
\Delta G_{k}=-R T \ln \left(C_{\phi} / K K K\right), \text { Дж/моль, }
$$

где $R$ - универсальная газовая постоянная равная 8,3144598 Дж/(моль $\left.{ }^{\circ} \mathrm{K}\right) ; T-$ температура смазочной среды, ${ }^{\circ}$ К; $C_{\phi}-$ концентрация фуллеренов в смазочной среде, размерность моль/м ${ }^{3} ; K K K$ - критическая концентрация кластерообразования из молекул фуллеренов, размерность моль/ $\mathrm{M}^{3}$.

Из формулы (4) можно получить выражение для определения количества кластеров:

$$
n_{k}=\frac{C_{\phi}}{\kappa К K}=\exp \left(\Delta G_{k} / R T\right), \text { шт. }
$$

Дипольный момент кластера $p_{k}$ определим по выражению, которое представлено в работе [9]:

$$
p_{k}=\sum_{i=1}^{n_{k}} p_{\phi} \cdot L\left(b_{k}\right), \text { Кл`м, }
$$

где $p_{\phi}$ - дипольный момент молекулы фуллерена, равен $3,34 \cdot 10^{-30}$ Кл м $2 L\left(b_{k}\right)-$ функция Ланжевена.

Функция Ланжевена на основании работы [9] определяется по выражению:

$$
L\left(b_{k}\right)=c t h b_{k}-1 / b_{k}, \text { Кл·м, }
$$

где $b_{k}$ - безразмерная величина, которая учитывает напряженность электростатического поля поверхности трения $E_{\text {п }}$ и температуру смазочной среды, что влияет на ориентацию кластеров относительно вектора напряженности электростатического поля поверхности трения:

$$
b_{k}=\frac{n_{k} \cdot p_{\phi} \cdot E_{n}}{k T}
$$

где $k$ - постоянная Больцмана, равная $1,380648 \cdot 10^{-23}$ Дж/ ${ }^{\circ} \mathrm{K}$.

Подставляя полученные выражения (5) - (8) в формулу (3) можно моделировать изменения напряженности электростатического поля смазочной среды при изменении концентрации фуллеренов, температуры и величины напряженности электростатического поля поверхности трения.

Третье слагаемое в правой части уравнения (1) определяет напряженность электростатического поля в объеме смазочной пленки за счет образования мицелл, где в качестве ядра выступает молекула фуллерена или кластер из фуллеренов, который окружают присоединенные молекулы высокомолекулярной кислоты (олеиновой, стеариновой и т.д.). Такие кислоты выступают в качестве «растворителя» фуллеренов. Выражение для определения величины электростатического поля за счет образования мицелл запишем в виде:

$$
E_{\mathcal{M}}=\frac{n_{M} p_{M}}{4 \pi \varepsilon \varepsilon_{0} d_{M}^{3}}, \mathrm{~B} / \mathrm{M},
$$

где $n_{м}$ - количество мицелл на единицу объема базового смазочного материала, шт; $p_{м}$ - дипольный момент мицеллы, Кл`м; $d_{м}-$ среднее расстояние между мицеллой и поверхностью трения, равное среднему размеру (диаметру) мицеллы, размерность м.

При достижении концентрации молекул фуллеренов и растворителярастительного масла, в объеме смазочного материала, которую называют крити- 
ческой концентрацией мицеллообразования (KKM), образуются агрегаты из однотипных молекул-мицелл.

Количество мицелл, которые могут образоваться в базовой смазочной среде определим на основании изменения энергии Гиббса [8]:

$$
\Delta G_{м}=-R T \ln \left(C_{\text {олк }} / K K M\right), \text { Дж/моль, }
$$

где $C_{\text {олк }}-$ концентрация фуллеренов и «растворителя» (растительного олеинового масла) в базовой смазочной среде, размерность моль/м ${ }^{3}$;

$K K M$ - критическая концентрация мицеллообразования, моль/м².

Исходя из (10) количество мицелл определим по выражению:

$$
n_{м}=\exp \left(\Delta G_{M} / R T\right), \text { шт. }
$$

Дипольный момент мицеллы определим из выражения [9]:

$$
p_{\text {м }}=\sum_{i=1}^{n_{M}} p_{\theta k} \cdot L\left(b_{M}\right), \text { Кл } \cdot \mathrm{M},
$$

где $p_{\mathrm{B} k}-$ дипольный момент молекулы высокомолекулярной кислоты, например, для олеиновой кислоты $p_{\mathrm{B} k}=4,84 \cdot 10^{-30}$ Кл`м.

Функция Ланжевена учитывает ориентацию мицелл в электростатическом поле, создаваемом поверхностью трения с учетом тепловых колебаний молекул:

$$
\begin{aligned}
& L\left(b_{M}\right)=c t h b_{M}-1 / b_{M}, \\
& b_{M}=\frac{n_{M} \cdot p_{6 k} \cdot E_{n}}{k T} .
\end{aligned}
$$

Подставляя полученные выражения (11) - (14) в формулу (9) можно моделировать изменения величины напряженности электростатического поля смазочной пленки при изменении концентрации растворителя фуллеренов, что приводит к образованию мицелл. Как следует из полученных выражений на процесс мицеллообразования, кроме концентрации растворителя фуллеренов, влияет температура смазочной среды и напряженность электростатического поля поверхности трения.

В процессе функционирования трибосистемы, за счет влияния температуры, а также нагрузки и скорости скольжения, процесс кластеро- и мицеллообразования, а также их разрушения, может происходить одновременно, следовательно, суммарное электростатическое поле смазочной среды $E_{ж}$ определяется как сумма:

$$
E_{\varkappa}=E_{k}+E_{\mathcal{M}}, \mathrm{B} / \mathrm{M} .
$$

Решением дифференциального уравнения (1) является функция:

$$
E(z)=\left(E_{n}+E_{ж}\right) \exp (-z), \mathrm{B} / \mathrm{M},
$$

где $\mathrm{z}$ - расстояние от поверхности трения по нормали, размерность мкм.

Результаты исследований. Результаты анализа решения дифференциального уравнения в виде функции (16) представлены на рис. 1 и рис. 2, а моделирования образования количества кластеров и мицелл в объеме смазочного материала на рис. 3 и рис. 4.

Обсуждение результатов исследований. Увеличение количества агрегатов (кластеров и мицелл) в объеме смазочного материала, рис.1, увеличивает суммарную напряженность электростатического поля смазочной пленки $E_{\text {ж}}$, которое формируется под действием электростатического поля поверхности трения $E_{\text {п }}$. При этом, применяя «растворитель» для фуллеренов в виде высокомолекуляр- 
ных кислот, можно добиться увеличения количество агрегатов более чем на порядок. Объясняется это тем, что при применении «растворителя» молекулы фуллерена в меньшей степени образуют в смазочном материале кластеры, а начинают активно образовывать мицеллы, что доказано в работе [1]. Ядром мицеллы выступает единичная молекула фуллерена или кластер из нескольких молекул фуллеренов с присоединенными к ядру полярными молекулами высокомолекулярной кислоты, например, олеиновой.

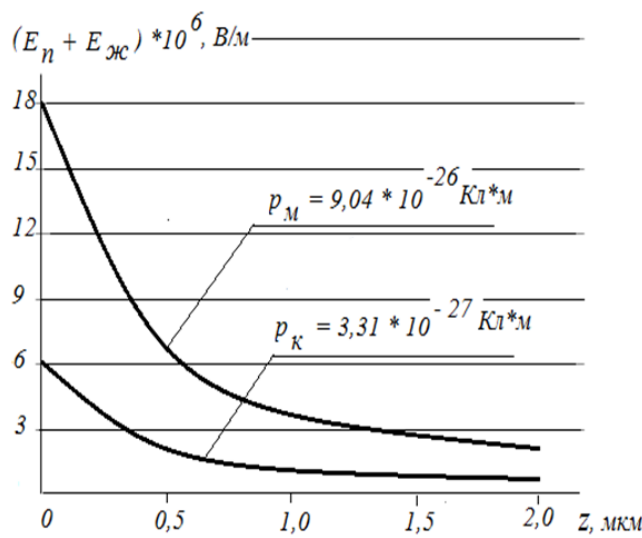

Рис. 1. Зависимости изменения напряженности электростатического поля в смазочной пленке от количества агрегатов и расстояния от поверхности трения

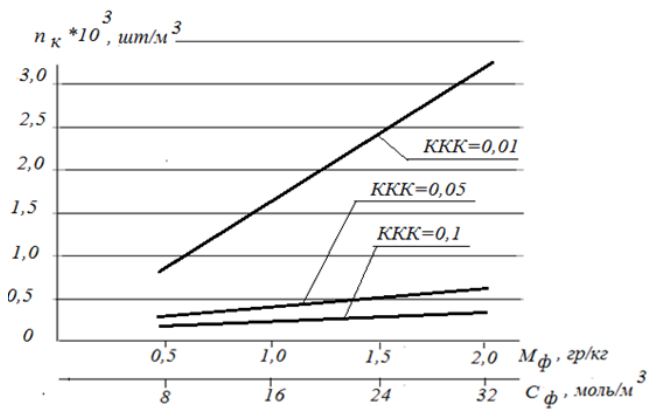

Рис. 3. Зависимости изменения количества кластеров от концентрации фуллеренов в растворе и критической концентрации кластерообразования

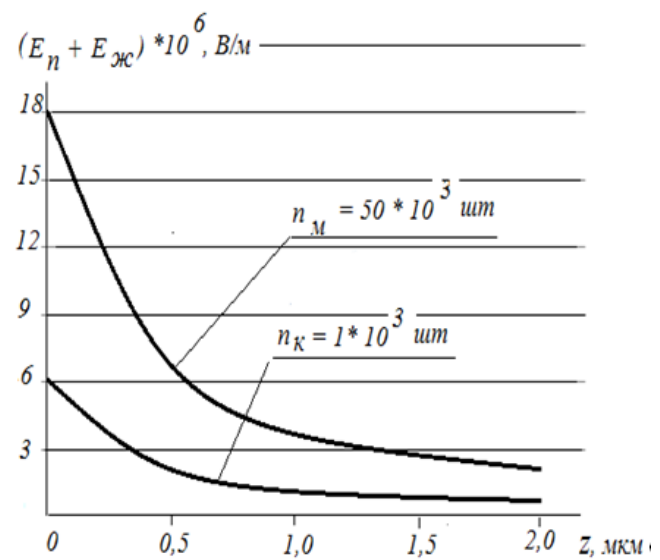

Рис. 2. Зависимости изменения напряженности электростатического поля в смазочной пленке от величины дипольного момента агрегатов и расстояния от поверхности трения

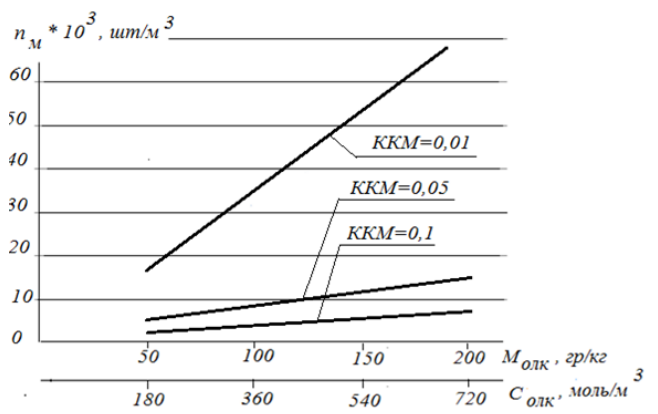

Рис. 4. Зависимости изменения количества мицелл от концентрации олеиновой кислоты в растворе и критической концентрации мицеллообразования

Необходимо отметить, что глубина проникновения электростатического поля в смазочный материал $Z$ не превышает 2 мкм. Согласно результатов проведенного численного анализа при $Z=2$ мкм величина суммарного электростатического поля уменьшается от $100 \%$ до $13 \%$.

Зависимости изменения суммарной напряженности электростатического поля в смазочной пленке от величины дипольного момента агрегатов и расстояния от поверхности трения представлены на рис.2. Из представленных зависимостей следует, что чем выше дипольный момент агрегатов, тем больше величина суммарной напряженности электростатического поля в объеме масляной пленки. Данный эффект будет положительно влияет на формирование структу- 
ры смазочной пленки на поверхности трения и на износостойкость трибосистемы. Увеличению дипольного момента агрегатов способствует формирование мицелл. Такой процесс можно вызвать применением «растворителя» фуллеренов с последующим введением в смазочный материал.

Как следует из теоретических зависимостей наиболее значимым фактором является критическая концентрация кластерообразования и мицеллообразования. Аналогичный вывод следует из зависимостей, представленных на рис. 3 и рис.4. Из зависимостей следует, что для увеличения числа агрегатов, которые

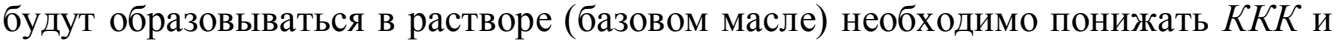
ККM. Одним из путей снижения критических концентраций является применение «сильных растворителей», например, растительных масел, которые содержат $72-82 \%$ масс. олеиновой кислоты и неограниченно растворяются в базовых технических маслах.

При достижении $K K K$ и $K K M$ в растворах начинают активно образовываться кластеры и мицеллы, а, следовательно, и изменяется дипольный момент таких агрегатов, формула (6) и формула (12). Под действием электростатического поля поверхности трения в объеме масляной пленки на поверхности трения формируется электростатическое поле жидкости.

Выводы. Из анализа решения дифференциального уравнения, которое описывает процесс взаимодействия электростатических полей установлено, что введение фуллеренов в базовый смазочный материал не приносит большого эффекта. Показано, что применение «растворителей» фуллеренов, в качестве которых могут выступать высокоолеиновые растительные масла, способствует мицеллообразованию в растворе, где ядром мицеллы является молекула фуллерена, окруженная молекулами олеиновой кислоты.

Установлено, что электростатическое поде поверхности трения является движущей силой для формирования электростатического поля в объеме масляной пленки, которая адсорбирована на поверхности трения. Показано, что на количество образованных кластеров и мицелл влияет критическая концентрация $K K K$ и $K K M$, которую можно изменять введением «растворителей» фуллеренов.

\section{Список литературы}

1. Безмельницын В. Н., Елецкий А. В., Окунь М. В.Фуллерены в растворах // Успехи физических наук. - 1998, № 11, 1195-1220

2. Гиндзбург Б. М., Байдакова М. В., Киреенко О. Ф. [и др.]. Влияние фуллеренов $\mathrm{C}_{60}$, фуллереновых саж и других углеродных материалов на граничное трение скольжение металлов // Журнал технической физики. - 2000, № 12, 87-97

3. Яхьяев Н. Я., Бегов Ж. Б., Батырмурзаев Ш. Д.Новая смазочная композиция для модификации поверхностей трибосопряжений судового малоразмерного дизеля // Вестник АГТУ. Сер.: Морская техника и технология. - 2009, № 1, 47-52

4. Семенов К. Н., Чарыков Н. А., Арапов О. В. [и др.]. Растворимость легких фуллеренов в некоторых эфирных и растительных маслах // Химия растительного сырья. 2010, № 2, 147-152

5. Кравцов А. Г. Разработка математической модели взаимодействия электрически активных гетерогенных мелкодисперсных систем на границе раздела поверхность трения - смазочная среда // Проблемитрибології. — 2017, № 1, 89-99

6. Кравцов А. Г. Моделирование формирования масляной пленки на поверхности трения при наличии фуллереновых добавок в смазочном материале и ее влияние на скорость изнашивания трибосистем // Проблемитрибології. — 2018, № 1, 69-77 
7. Фроленкова Л. Ю., Шоркин В. С. Метод вычисления поверхностной энергии и энергии адгезии упругих тел // Вестник ПНИПУ: Механика - 2013, № 1, 235-259

8. Базаров И.П. Термодинамика / И.П. Базаров. - М.: Высш. Школа, 1991. - 376 с.

9. Лысиков Е.Н. Надмолекулярные структуры жидких смазочных сред и их влияние на износ технических систем / Е.Н. Лысиков, В. Б. Косолапов, С.В. Воронин. - Харьков: ЭДЭНА, 2009. - 274 c.

Стаття надійшла до редакції 10.09.2020.

Войтов Віктор Анатолійович - д.т.н., професор, завідувач кафедри транспортних технологій і логістики Харківського національного технічного університету сільського господарства ім. П. Василенка, м. Харків, Україна, vavoitovva@gmail.com

Кравцов Андрій Григорович - К.т.н., доцент, декан факультету технологічних систем і логістики Харківського національного технічного університету сільського господарства ім. П. Василенка, м. Харків, Україна, kravcov@gmail.com

\section{В. А. ВОЙТОВ, А. Г. КРАВЦОВ}

\section{ТЕОРЕТИЧНІ ДОСЛІДЖЕННЯ ПРОЦЕСУ ФОРМУВАННЯ МАСТИЛЬНОЇ ПЛІВКИ НА ПОВЕРХНІ ТЕРТЯ ЗА НАЯВНОСТІ ФУЛЕРЕНІВ В ЗМАЩУВАЛЬНОМУ МАТЕРІАЛІ}

В роботі представлені результати теоретичних досліджень по формуванню мастильної плівки на поверхні тертя при наявності фулеренів в змащувальному матеріалі. Показано, що збільшення кількості агрегатів (кластерів і міцелл) в об ємі змащувального матеріалу збільшує сумарну напруженість електростатичного поля мастильної плівки, яке формується під дією електростатичного поля поверхні тертя. При цьому, застосовуючи «розчинник» для фулеренів у вигляді високомолекулярних кислот, кількість агрегатів збільшується на порядок. При застосуванні «розчинника» молекули фулерену в меншій мірі утворюють в змащувальному матеріалі кластери, а починають активно утворювати міцели. Ядром міцели виступає одинична молекула фулерену або кластер з декількох молекул фулеренів з приєднаними до ядру полярними молекулами високомолекулярної кислоти, наприклад, олеїнової. Глибина проникнення електростатичного поля в мастильний матеріал не перевищує 2 мкм і зменшується від 100\% до $13 \%$.

Представлені залежності зміни сумарної напруженості електростатичного поля в мастильної плівці від величини дипольного моменту агрегатів і відстані від поверхні тертя. Показано, що чим вище дипольний момент агрегатів, тим більше величина сумарної напруженості електростатичного поля в об'ємі масляної плівки. Такий процес можна викликати застосуванням «розчинника» фулеренів з подальшим введенням в змащувальний матеріал.

Показано, що одним із шляхів зниження критичних концентрацій $є$ застосування «сильних розчинників», наприклад, рослинних олій, які містять 72 - 82\% мас. олеїнової кислоти і необмежено розчиняються в базових технічних оливах.

Ключові слова: мастильний матеріал; фулерени; рослинні олії; технічні оливи; електростатичне поле поверхні тертя; електростатичне поле мастильної плівки; кластери; міцели; критична концентрація агрегатів 


\section{A. VOJTOV, A. G. KRAVCOV \\ THEORETICAL STUDIES OF THE OIL MEMBRANE FORMATION ON THE FRICTION SURFACE IN THE PRESENCE OF FULLERENES IN THE LUBRICANT}

The paper presents the results of theoretical studies on the formation of an oil membrane on the friction surface in the presence of fullerenes in the lubricant. It is shown that an increase in the number of aggregates (clusters and micelles) in the volume of the lubricant increases the total electric field strength of the lubricating membrane, which is formed under the action of the electrostatic field of the friction surface. In this case, applying «solvent» for fullerenes in the form of high molecular weight acids, the number of aggregates increases by an order of magnitude. When using a «solvent», fullerene molecules form clusters in the lubricant to a lesser extent, and begin to actively form micelles. The nucleus of a micelle is a single fullerene molecule or a cluster of several fullerene molecules with polar molecules of a high molecular weight acid attached to the nucleus, for example, oleic. The penetration depth of the electric field into the lubricant does not exceed $2 \mu \mathrm{m}$ and decreases from $100 \%$ to $13 \%$.

The dependences of the change in the total electric field strength in the lubricating membrane on the value of the dipole moment of the aggregates and the distance from the friction surface are presented. It is shown that the higher the dipole moment of the aggregates, the greater the value of the total electric field strength in the volume of the oil membrane. Such a process can be triggered by the use of a fullerene «solvent» with subsequent introduction into the lubricant. It is shown that one of the ways to reduce critical concentrations is to use «strong solvents», for example, vegetable oils that contain $72-82 \%$ masses. Oleic acid and dissolve indefinitely in technical base oils.

Keywords: lubricant; fullerenes; vegetable oils; friction surface electrostatic field; friction surface electrostatic field; clusters; micelles; critical concentration of aggregates

\section{References}

1. Bezmel'nicyn V. N., Eleckij A. V., Okun' M. V.Fullereny v rastvorah // Uspehi fizicheskih nauk. - 1998, № 11, 1195-1220

2. Gindzburg B. M., Bajdakova M. V., Kireenko O. F. [i dr.]. Vlijanie fullerenov S60, fullerenovyh sazh i drugih uglerodnyh materialov na granichnoe trenie skol'zhenie metallov // Zhurnal tehnicheskoj fiziki. — 2000, № 12, 87-97

3. Jah'jaev N. Ja., Begov Zh. B., Batyrmurzaev Sh. D.Novaja smazochnaja kompozicija dlja modifikacii poverhnostej tribosoprjazhenij sudovogo malorazmernogo dizelja // Vest-nik AGTU. Ser.: Morskaja tehnika i tehnologija. — 2009, № 1, 47-52

4. Semenov K. N., Charykov N. A., Arapov O. V. [i dr.]. Rastvorimost' legkih fulle-renov v nekotoryh jefirnyh i rastitel'nyh maslah // Himija rastitel'nogo syr'ja. — 2010, № 2, 147-152.

5. Kravcov A. G. Razrabotka matematicheskoj modeli vzaimodejstvija jelektricheski aktivnyh geterogennyh melkodispersnyh sistem na granice razdela poverhnost' tre-nija — smazochnaja sreda // Problemitribologiï. — 2017, № 1, 89-99

6. Kravcov A. G. Modelirovanie formirovanija masljanoj plenki na poverhnosti trenija pri nalichii fullerenovyh dobavok v smazochnom materiale i ee vlijanie na sko-rost' iznashivanija tribosistem // Problemitribologiii. — 2018, № 1, 69-77

7. Frolenkova L. Ju., Shorkin V. S. Metod vychislenija poverhnostnoj jenergii i jenergii adgezii uprugih tel // Vestnik PNIPU: Mehanika — 2013, № 1, 235-259

8. Bazarov I.P. Termodinamika / I.P. Bazarov. - M.: Vyssh. Shkola, 1991. - 376 s.

9.Lysikov E.N. Nadmolekuljarnye struktury zhidkih smazochnyh sred i ih vlijanie na iznos tehnicheskih sistem / E.N. Lysikov, V. B. Kosolapov, S.V. Voronin. - Har'kov: JeDJeNA, 2009. - $274 \mathrm{~s}$. 